\title{
Lead industry life cycle studies: environmental impact and life cycle assessment of lead battery and architectural sheet production
}

\author{
Alistair J. Davidson $^{1}$ (D) S Steve P. Binks ${ }^{1} \cdot$ Johannes Gediga $^{2}$ \\ Received: 14 May 2015 / Accepted: 22 December 2015 /Published online: 22 January 2016 \\ (C) The Author(s) 2016. This article is published with open access at Springerlink.com
}

\begin{abstract}
Purpose This paper will give an overview of LCA studies on lead metal production and use recently conducted by the International Lead Association.

Methods The lead industry, through the International Lead Association (ILA), has recently completed three life cycle studies to assess the environmental impact of lead metal production and two of the products that make up approximately $90 \%$ of the end uses of lead, namely lead-based batteries and architectural lead sheet.

Results and discussion Lead is one of the most recycled materials in widespread use and has the highest end-of-life recycling rate of all commonly used metals. This is a result of the physical chemical properties of the metal and product design, which makes lead-based products easily identifiable and economic to collect and recycle. For example, the end-oflife collection and recycling rates of lead automotive and industrial batteries and lead sheet in Europe are 99 and $95 \%$, respectively, making them one of the few products that operate in a true closed loop. These high recycling rates, coupled with the fact that both lead-based batteries and architectural lead sheet are manufactured from recycled material, have a beneficial impact on the results of LCA studies, significantly lowering the overall environmental impact of these products. This
\end{abstract}

Responsible editor: Andrea J, Russell-Vaccari

Alistair J. Davidson

davidson@ila-lead.org

1 International Lead Association, Bravington House, 2 Bravingtons Walk, London N1 9AF, UK

2 thinkstep AG, Hauptstraße 111-113, 70771 Leinfelden-Echterdingen, Germany means that environmental impacts associated with mining and smelting of lead ores are minimised and in some cases avoided completely. The lead battery LCA assesses not only the production and end of life but also the use phase of these products in vehicles. The study demonstrates that the technological capabilities of innovative advanced lead batteries used in start-stop vehicles significantly offset the environmental impact of their production. A considerable offset is realised through the savings achieved in global warming potential when lead-based batteries are installed in passenger vehicles with start-stop and micro-hybrid engine systems which have significantly lower fuel consumption than regular engines. Conclusions ILA has undertaken LCAs which investigate the environmental impact associated with the European production of lead metal and the most significant manufactured lead products (lead-based batteries used in vehicles and architectural lead sheet for construction) to ensure up-to-date and robust data is publically and widely available.

Keywords Construction · Lead · Lead-acid batteries · Lead-based batteries · Lead sheet · Life cycle analysis · Recycling

\section{Introduction}

Life cycle assessment (LCA) is one of the tools that is increasingly being used to examine the environmental impact of a product through its entire life cycle. For metals, a typical 'cradle-to-grave' LCA study covers the mining and extraction of raw materials, their fabrication, use, and recycling/disposal and includes energy and transportation considerations and all the other product supplies required.

Relatively few LCAs have been conducted and made publically available assessing the environmental impact of lead 
production and that of lead products. In 1998, the North American Lead Association published their first life cycle inventory (LCI) dataset for primary and secondary lead production (ILZRO 1998 internal report). This comprehensive inventory of the state of North American lead and leadbased battery production facilities provided insight into all the input and output process flows, including energy, natural resource consumption, and process emissions (air, water, and solid waste). This data set was made available through the European Life Cycle Database and Ecoinvent in the past, however is now considered outdated due to the data being over 15 years old.

More data is available in the literature regarding the comparison of lead batteries with other battery technologies. For example, studies have been conducted recently assessing the life cycle environmental impacts and life cycle costs of electric motorcycles (Kerdlap 2014) and of batteries for electric vehicles under different charging regimes (Matheys et al. 2006). However, these studies were not representative of the major use of lead batteries, i.e. starter lighter ignition use in automotive applications. The most recent battery comparison study published in public literature was an evaluation conducted on the cradle-to-gate life cycle inventory studies of lead-acid, nickel-cadmium, nickel-metal hydride, sodium-sulphur, and lithium-ion battery technologies (Sullivan and Gaines 2010). This study reported that 'Either on a per kilogram or per watthour capacity basis, lead-acid batteries have the lowest production energy, carbon dioxide emissions, and criteria pollutant emissions'. As far as the authors are aware, no comparative LCA studies have been published for architectural lead sheet.

However, all studies referenced above are based on LCA data for lead production that is at lead 10 years old. As a result, the authors of this paper initiated lifecycle studies to ensure up to date and robust data is publically and widely available for primary (sourced from lead containing ores and concentrates) and secondary (sourced from recycled scrap) lead production and for the two major uses of lead, namely lead-based batteries and lead sheet. This is discussed further in the sections below.

\section{Lead production LCA}

In 2013, International Lead Association (ILA), in conjunction with PE International, published a European Life Cycle Inventory study of primary and secondary lead production, with the aim of providing reliable and robust life cycle inventory (LCI) data to the market. The existing LCI data did not reflect the current status in terms of:

- Energy efficiency of smelting

- Data availability
- Geographical coverage

- Representation in terms of EU-27 production capacity

The LCA study was conducted according to the requirements of the International Organization for Standardization ISO 14040 and ISO 14044 to withstand the critical review. The LCI data is available in the European Life Cycle Database (ELCD), the Gabi Database (University of Stuttgart und PE International AG (2006)), and through the International Lead Association Website (www.ila-lead.org). In the study, sitespecific data representative of current technologies used in the lead industry for the reference year 2008/2009 were collected and analysed. The smelting technologies considered in the study are italicised in Table 1. Unfortunately, the whole range of production processes available were not evaluated, as not all European lead-producing companies participated in the study. However, these three technologies represent over $80 \%$ of the technology in use on the EU-27 market.

In the study, a horizontal averaging methodology (where each process in the production route was averaged across all participating companies) was chosen to be able to benchmark between company specific processes and the calculated average.

For secondary lead production the following process flow was chosen (Fig. 1).

The functional unit, which enables the system inputs/ outputs to be quantified and assessed, was selected as $1 \mathrm{~kg}$ of refined lead $(99.99 \%)$ at gate. Mass allocation procedures were applied in line with the information detailed in the metals industry guidance document on allocation (Santero and Henry 2014). The primary and secondary metal co-products that occur in the considered system boundaries are:

- Copper matte

- Zinc

- Silver

- Lead alloys (PbCa, PbCu, PbSb, PbSn, PbTn...)

The following environmental impact categories and indicators were considered in the scope of this study:

- Primary energy demand-PED

- Global warming potential-GWP
Table 1 Furnace technologies used for smelting in the lead industry. Sections in italics indicated furnaces covered by ILA LCI study

\begin{tabular}{ll}
\hline Technology & Acronym \\
\hline Blast furnace & BF \\
QSL process & QSL \\
Rotary furnace & RR \\
Top submerged lancing & TSL \\
Continuous flash smelting & CF \\
Top blown rotary converter & TBRC \\
\hline
\end{tabular}


Fig. 1 Process flows for lead production LCI

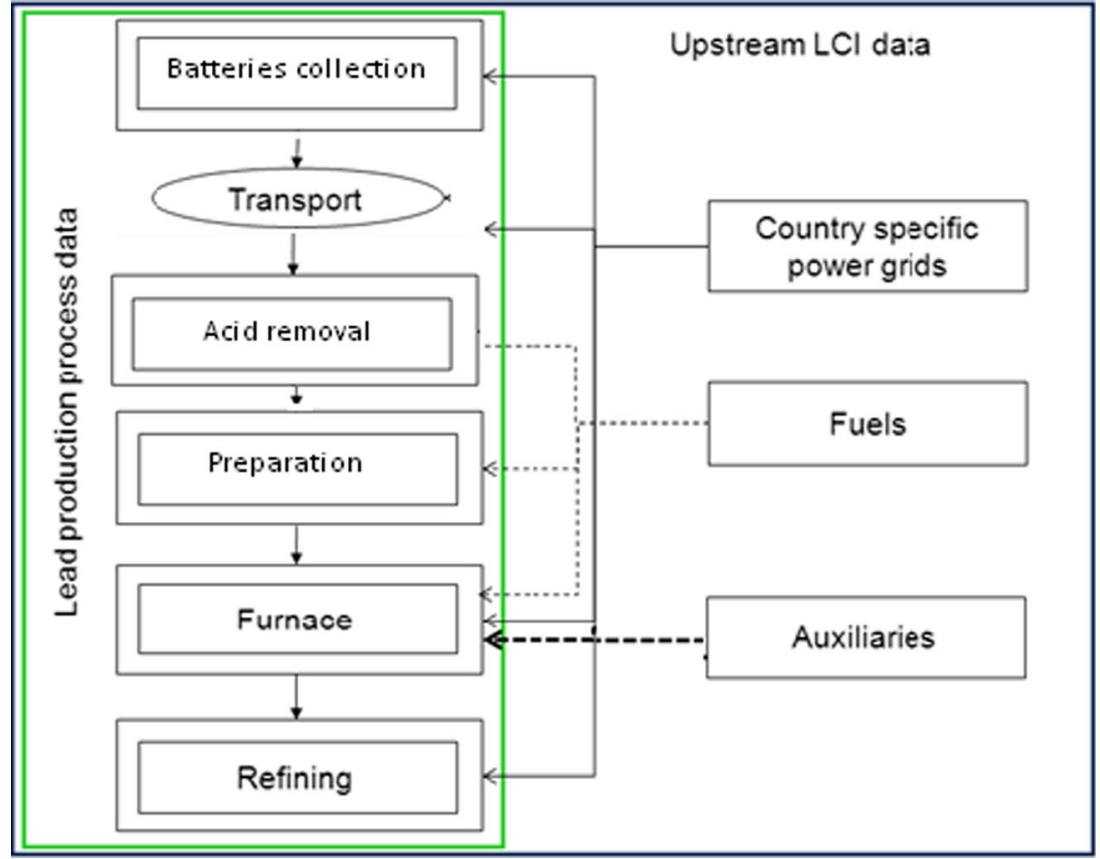

- Acidification potential-AP

- Eutrophication potential-EP

- Photochemical ozone creation (smog creation)-POCP

These five impact categories were chosen to be in line with the impact categories made publically available by other metals commodities representing the non-ferrous metals industry. An impact category reflecting toxicity was not provided as it is considered that the models that are used to calculate toxicity potentials within LCA are under continuous development (compared to the above selected categories) and do not reflect a stable or profound result. The characterisation factors for toxicity are extremely variable from generation to generation. These values can therefore not be recommended for reliable decision support. The Centruum voor Milieukunde Leiden (CML) methodology was selected as they have a European context and are widely used and respected within the LCA community (Guinée et al. 2001).

\subsection{Results and interpretation-lead production LCI}

An overview over the main results for the impact categories considered in the study is shown in Table 2.

The main contributors to all impact categories are 'mining and concentrate' and 'smelting'. This can be seen in terms of global warming potential in Fig. 2. The gas treatment phase refers to all those emissions which could not be assigned to the different processes.

Figure 2 also shows that the second highest contribution to the environmental impact of $1 \mathrm{~kg}$ of lead is from mining and concentration, accounting for $32 \%$ of the impact. In Europe, $44 \%$ of lead production originates from primary sources and $56 \%$ is produced by recycling secondary material. It can therefore be seen that if mining and concentration was not considered (e.g. if you imagined all lead was produced from secondary production) and you make the assumption that the impact for smelting and refining is in the same order of magnitude for primary and secondary production, the overall impact would be significantly reduced. This gives rise to the assumption that higher recycling of lead products such as lead batteries or lead sheet leads to reduction of their environmental impacts. This assumption is reflected in the LCAs for lead batteries and lead sheet.

The source of the Greenhouse Gas emissions is shown in the Fig. 3. Direct emissions from smelting and indirect GHG emissions from power generation are the main contributors to the total GWP. Oxygen and coal production contribute only negligibly to the GWP.

\subsection{Conclusion-lead production LCI}

The results of the study show that the mining and concentration for the production of $1 \mathrm{~kg}$ of refined lead is one of the

Table 2 Impact category analyses in lead production LCI and associated values for $1 \mathrm{~kg}$ of lead

\begin{tabular}{lc}
\hline Impact category (unit) & Value \\
\hline Primary energy demand (MJ) & 18.5 \\
Global warming (kg. $\mathrm{CO}_{2}$ eq.) & 1.31 \\
Acidification (kg. $\mathrm{SO}_{2}$ eq.) & 0.01 \\
Eutrophication (kg. $\mathrm{PO}_{4}$ eq.) & $5.61 \mathrm{E}-4$ \\
Photo oxidant formation (kg. ethene eq.) & $4.73 \mathrm{E}-4$ \\
\hline
\end{tabular}


Fig. 2 Cradle-to-gate results for lead production LCI in terms of global warming potential
Cradle to gate results $\times 1 \mathrm{~kg}$ refined lead

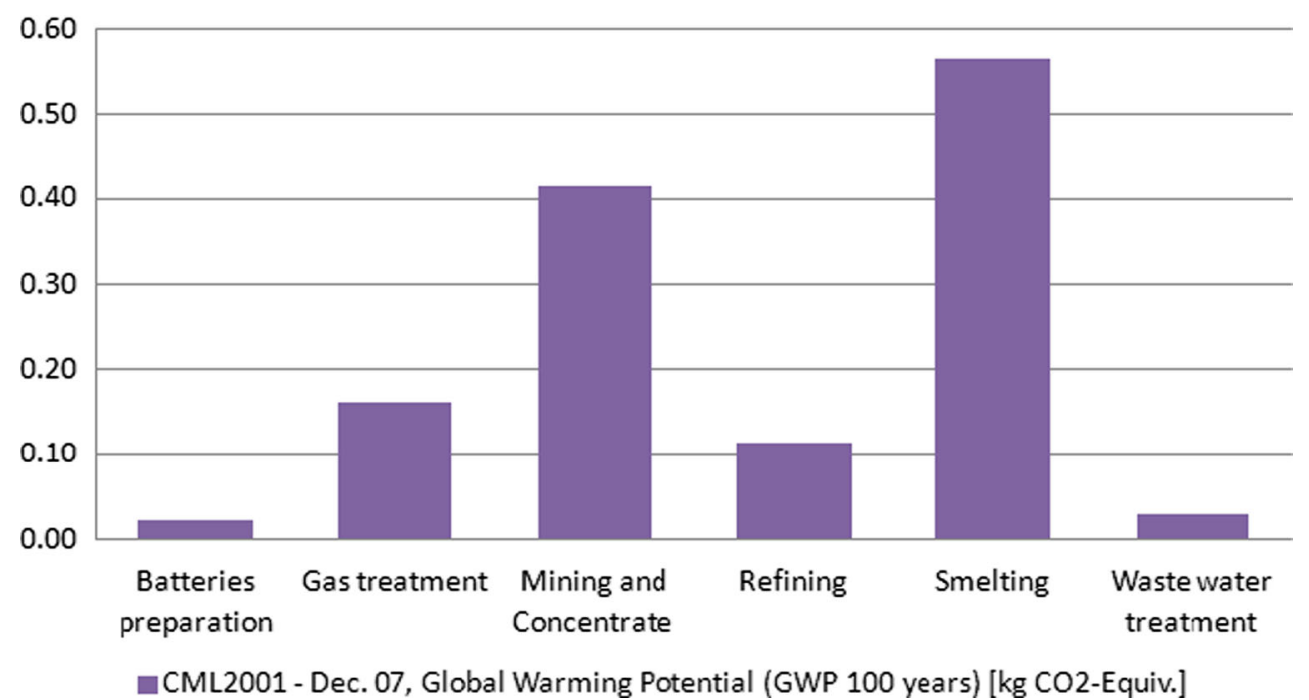

bigger contributors to the total impact of lead production besides smelting. This is the case for all impact categories. The main contributors in mining and concentration are the fuel combustion of hauling trucks in the mining operation (included in the onsite emissions in Fig. 3) and power production. The use of explosives in mining also has a high impact on the Eutrophication potential, which is caused during the production of the explosive Ammonium nitrate.

The main limitation of this study in terms of representativeness was the number of participant companies in the study. However, although only $32 \%$ of ILA member companies participated in the study, their production technologies represent $80 \%$ of that currently in use. A commitment of over $75 \%$ of the member companies would be a better representative dataset for the entire lead industry in Europe, and this data is expected to be updated in the near future. This is discussed further in Section 6-'Future work'. The data generated

\section{GWP - cradle to gate results}

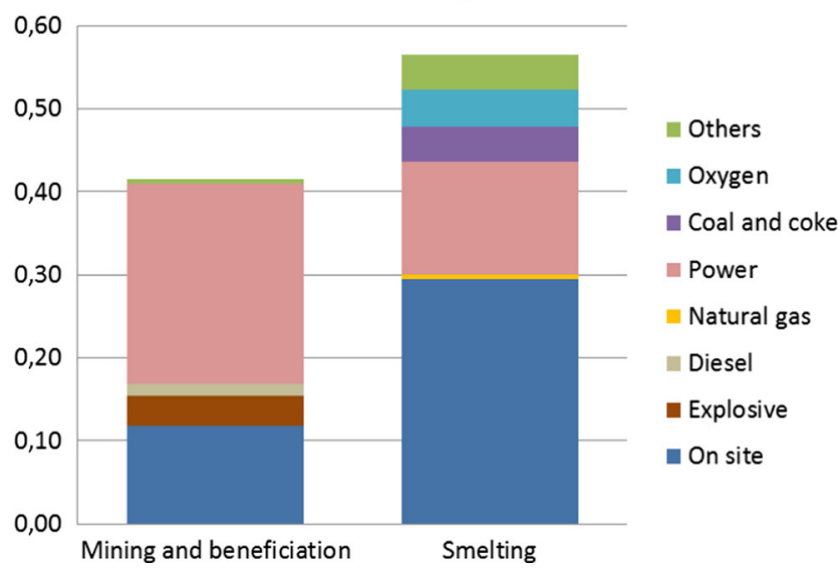

Fig. 3 Cradle-to-gate results for lead production LCI in terms of source of global warming potential though this project was used as an input to the LCA studies discussed in Sections 3 and 4 for lead batteries and lead sheet.

\section{Lead battery LCA}

Currently, the major use of refined lead is in lead-based batteries. In recent times, global lead production has risen from 5 million tonnes per annum in the 1970 to 11 million tonnes in 2013 (International Lead Zinc Study Group 2015a, b), primarily due to the increase in demand for lead-acid batteries. Leadacid batteries are the mainstay of global storage technologies for renewable energy sources, such as solar cell and wind turbines. Lead batteries are also widely used automotive applications, being the only mass market technology for SLI (starter lighter ignition) in conventional vehicles (cars, trucks, buses, motorbikes) and in start-stop and micro-hybrid systems. Lead batteries are also used as auxiliary batteries in electric vehicles and hybrid vehicles to supply the electric components including safety features (Joint industry analysis 2014). Furthermore, lead batteries are vital as a back-up emergency power supply in case of main power failure in hospitals, telephone exchanges, mobile phone networks, and public buildings and for the emergency services (International Lead Zinc Study Group 2015a, b).

The global demand for automotive and industrial batteries has changed significantly over the years. Figure 4 identifies the end uses of lead in 1960 compared with today. The increasing use of refined lead metal in battery production can clearly be seen, and today, the use of lead in batteries accounts for more than $90 \%$ of the entire lead market (ca. $10 \times 10^{6} \mathrm{t}$ ). An eightfold growth rate between 1970 and 2014 corresponds to the increase in the number of automobiles worldwide. Automotive batteries for starting, lighting, and ignition (SLI) 
Fig. 4 Global applications of lead from 1960 to 2014. The use of lead-based batteries has increased significantly over time and now account for ca. $90 \%$ of the use of refined lead metal

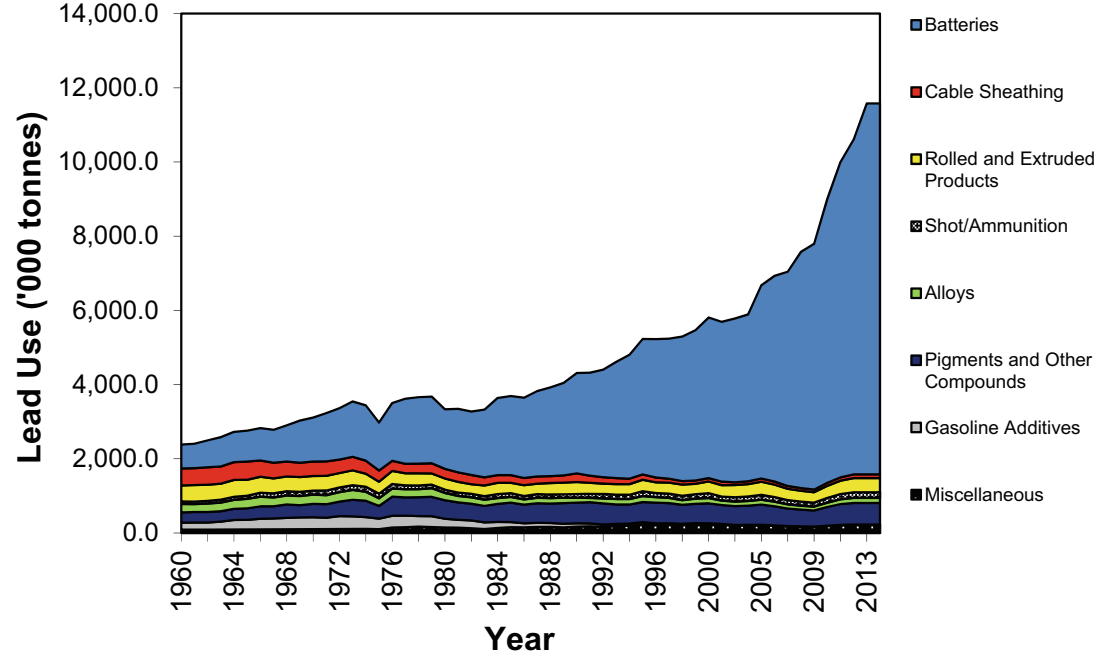

and traction batteries/stationary batteries (used for standby and emergency power supply) account for approximately 75 and $25 \%$ of total battery lead consumption respectively.

In 2014, the key players in the supply chain for lead-based automotive batteries conducted a study to assess the impact of this product in its various applications on the environment (PE International 2014-internal report). Due to confidentiality issues, the full report is not currently publically available. However, the executive summary is available from the European Car Manufacturers Association web page (ACEA 2015). This Life Cycle Assessment study was commissioned by EUROBAT (Association of European Automotive and Industrial Battery Manufacturers), ILA, ACEA (The European Automobile Manufacturers Association), JAMA (Japan Automobile Manufacturers Association), and KAMA (Korean Automobile Manufacturers Association), which together represents the majority of Europe's battery and automobile manufacturers, along with Japanese and Korean automobile manufacturers and the international lead industry. This study, conducted according to rules and methodologies defined by ISO Standards 14040 (2006) and 14044 (2006), was a comprehensive evaluation of the three main automotive battery types from a cradle-to-grave perspective and reported on their life cycle environmental performance. A third party critical review was conducted by Prof. Dr. Matthias Finkbeiner, from the Technical University Berlin, Germany.

Three lead-based battery applications were chosen for consideration in this study, with the contributing industry data representing more than $90 \%$ of the production volume for those technologies in Europe:

- Standard technology batteries: Flooded lead-based batteries used in conventional vehicles, for starting the internal combustion engine (ICE) and lighting and ignition systems - commonly known as starting, lighting, and ignition (SLI).
- Improved technology batteries: Enhanced flooded (EFB) or absorbent glass matt (AGM) lead-based batteries used in vehicles with a start-stop system, which allows the ICE to automatically shut down under braking and rest and then to restart.

- Advanced technology batteries: EFB or AGM lead-based batteries used in vehicles with a micro-hybrid system, which combines start-stop functionality with regenerative braking (a system to recover and restore energy from braking) and other micro-hybrid features that require higher deep-cycle resistance and charge recoverability from the battery.

The rechargeable batteries referenced above have the function of providing electric energy to vehicles to cover several functionalities (e.g. starting, braking, lighting, etc.) available in conventional, micro-hybrid vehicles, which have the function of providing transport services. The functional unit of the study was one lead-based battery with the capacity of $70 \mathrm{Ah}$ applied to vehicles. An average of the weights of the batteries produced by the participants was selected to define the reference flow, in order to calculate the environmental impacts. The parameters listed in Tables 3 and 4 were assigned to the different battery technologies.

As with the lead production work, the CML methodology was used regarding impact categories. However, between the time that the lead production LCA was conducted and the lead battery LCA, there had been many developments and discussions in the realm of LCIA methods, which meant that additional impact categories were also considered. This included:

- Abiotic depletion potential (elementary)-ADPe

- Abiotic depletion potential (fossil)-ADPf

- Acidification potential-AP

- Eutrophication potential-EP

- Global warming potential-GWP 
Table 3 Technical parameter per battery technology

\begin{tabular}{llllll}
\hline Battery & Average battery weight $(\mathrm{kg})$ & Capacity $(\mathrm{Ah})$ & Application & Cold cranking performance (CCA) & Lifespan (years) \\
\hline Standard technology & 18 & 70 & Conventional SLI & 570 & 5 \\
Improved technology & 19 & 70 & Start-stop & 680 & 5.5 \\
Advanced technology & 20 & 70 & Micro-hybrid & 760 & 6 \\
\hline
\end{tabular}

${ }^{\text {a }} \mathrm{CCA}$ refers to the rating used in the battery industry to define a battery's ability to start an engine in cold temperatures

- Photochemical ozone creation potential-POCP

- Primary energy demand-PED

As in the case of lead production, an impact category reflecting toxicity was not provided as it is considered that the models that are used to calculate toxicity potentials within LCA are under continuous development (compared to the above selected categories) and do not reflect a stable or profound result.

The life cycle assessment of the batteries was performed in two levels/systems:

A. Cradle-to-gate system: This included the extraction of the raw materials and transport, the production of battery parts, and assembly.

B. Cradle-to-gate+use stage: This included the cradle-togate battery system A with the use stage.

Mass allocation was applied by each company before averaging. For each battery, different scenarios were created according to the battery technology and corresponding use stage (application).

\subsection{Results and interpretation—battery LCA}

\subsubsection{System A-manufacturing stage}

For all battery technologies, the contribution of lead production to the impact categories under consideration was in the range of 40 to $80 \%$ of total cradle-to-gate impact, making it the most dominant contributor in the production phase (system A) of the life cycle of lead-based batteries. This can be seen in Figs. 5, 6, and 7 which show the CML impact for standard, improved, and advanced technology batteries.
Amongst the batteries under consideration, the differences in impacts and emissions relate to the location of the production site (or specific location-mix of sites) in addition to the technology or battery composition itself. Different countries and sites operate have different emission levels, and these are reflected in a production mix when multiple geographic locations are averaged. This is shown in Figs. 5, 6, and 7 in battery production, electricity, thermal energy, and waste treatment.

\subsubsection{System B-system $A+$ use phase}

The batteries are required in conventional, start-stop, and micro-hybrid vehicles. The latter two feature reduced fuel consumption and emissions when compared to conventional applications. Although the Improved technology and advanced technology batteries contain more lead (18\% more than standard technology batteries) and have slightly higher impact in the production phase ( 3 and $5 \%$ higher GWP respectively), these batteries contribute significantly to fuel savings in the vehicle they are used in. Improved and advanced technology lead-based batteries bring positive environmental benefits through reduction of fuel consumption by $2-10 \%$ (depending on the battery technology and vehicle type) in the use phase. Therefore used in their respective start-stop and micro-hybrid applications, the batteries result in GWP savings of $700 \mathrm{~kg} \mathrm{CO}_{2}$ eqv. and $1600 \mathrm{~kg} \mathrm{CO}_{2}$ eqv., respectively. This corresponds to 25 times and 55 times the entire manufacturing phase GWP of standard technology batteries. These fuel savings more than compensate for all global warming potential resulting from the battery production - this can be seen clearly in Fig. 8 .

Another significant observation from the study was that the battery's overall environmental footprint during manufacturing is negligible in comparison with the manufacture of the

Table 4 Further parameters per battery technology

\begin{tabular}{|c|c|c|c|c|}
\hline Battery & Application & $\begin{array}{l}\text { Lifetime of vehicle [distance } \\
(\mathrm{km}) \text { and time (years)] }\end{array}$ & Litre/100 km & $\begin{array}{l}\text { No. of batteries during } \\
\text { lifetime of vehicle }\end{array}$ \\
\hline Standard technology & Conventional SLI & $150,000 \mathrm{~km}-10$ years & 5.1 & 2.18 \\
\hline Improved technology & Start-stop & $150,000 \mathrm{~km}-10$ years & $5.0-4.85$ & 1.8 \\
\hline Advanced technology & Micro-hybrid & $150,000 \mathrm{~km}-10$ years & $4.85-4.6$ & 1.7 \\
\hline
\end{tabular}


Fig. 5 System A resultsmanufacturing of standard battery technology
Contribution Analysis (Standard Technology batteries)

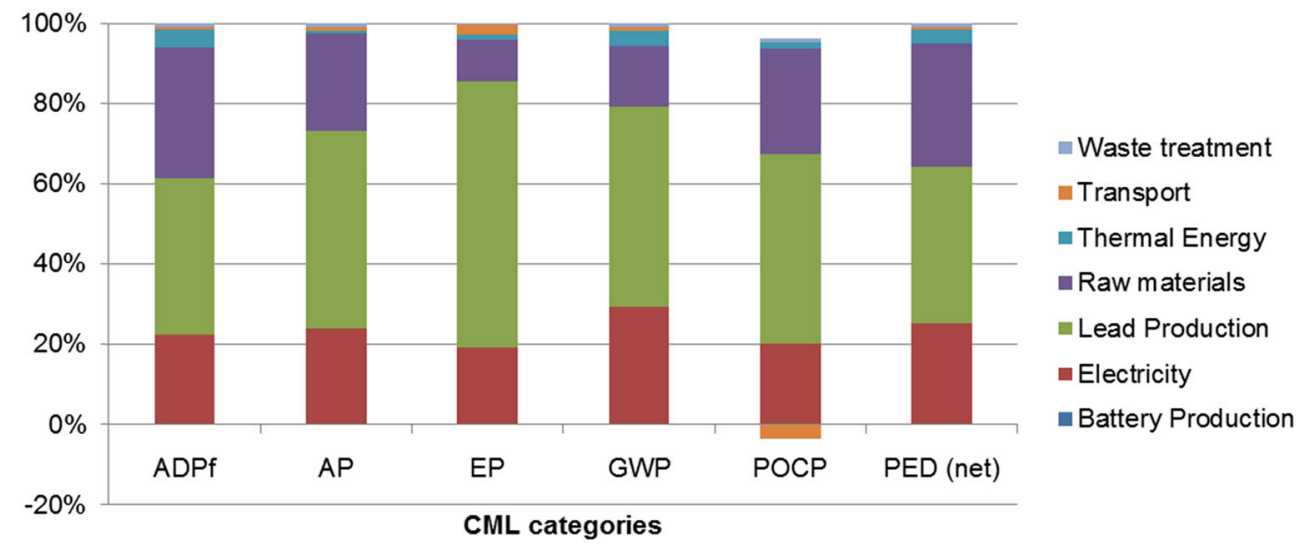

overall vehicle (e.g. the data was compared with the Mercedes 300 hybrid which has 9.9 t $\mathrm{CO}_{2}$ emissions).

Two scenarios were calculated in this study, for the end-oflife of lead batteries. In the first, 'open loop scenario', the lead batteries are recycled and the lead produced substitutes primary lead on the market. Thereby, it results in environmental credit or avoided burden. In the second, the recycled lead from batteries is assumed to all recirculate through the identical production processes to be made into new lead batteries. In this case, no consideration of avoided burden is necessary. Owing to the high take collection and recycling rates of automotive lead batteries in Europe (>99 \%-IHS 2014), the closed loop scenario modelling approach most closely mirrors the real world material flow.

Using the 'closed loop' methodology, there was a lower contribution from production and a greater proportion comes from battery recycling. This is due to a lower amount of impacts from the production module as more secondary/recycled lead is fed back into the system.
The 'open loop' methodology resulted in environmental credits to the system in the order of magnitude of 10-20\% of total absolute impact to the system. The lead recycled at the end-of-life was considered to be reusable as a substitute for producing primary lead from mining ore, and hence, the 'avoided burden' or primary lead production is credited to the system under consideration.

Both open and closed loop approaches presented similar benefits as both represent the substitution of primary lead with secondary lead, thereby reducing the environmental burden from the production (mining, concentration, etc.) of lead from ore.

\subsection{Conclusion-battery LCA}

The following conclusions were drawn from the study:

Vehicle production has a greater impact than battery production-battery manufacturing and assembly processes as such do not play a dominant role in the environmental impacts
Fig. 6 System A resultsmanufacturing of improved battery technology
Contribution Analysis (Improved Technology batteries)

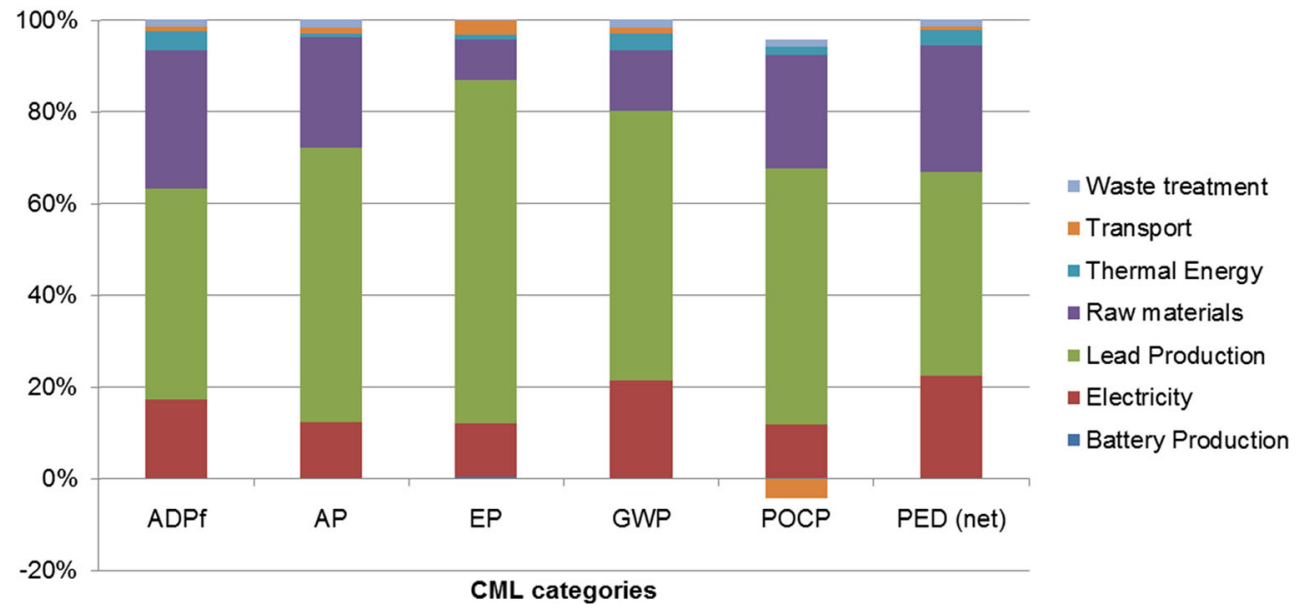


Fig. 7 System A resultsmanufacturing of improved battery technology
Contribution Analysis (Advanced Technology batteries)

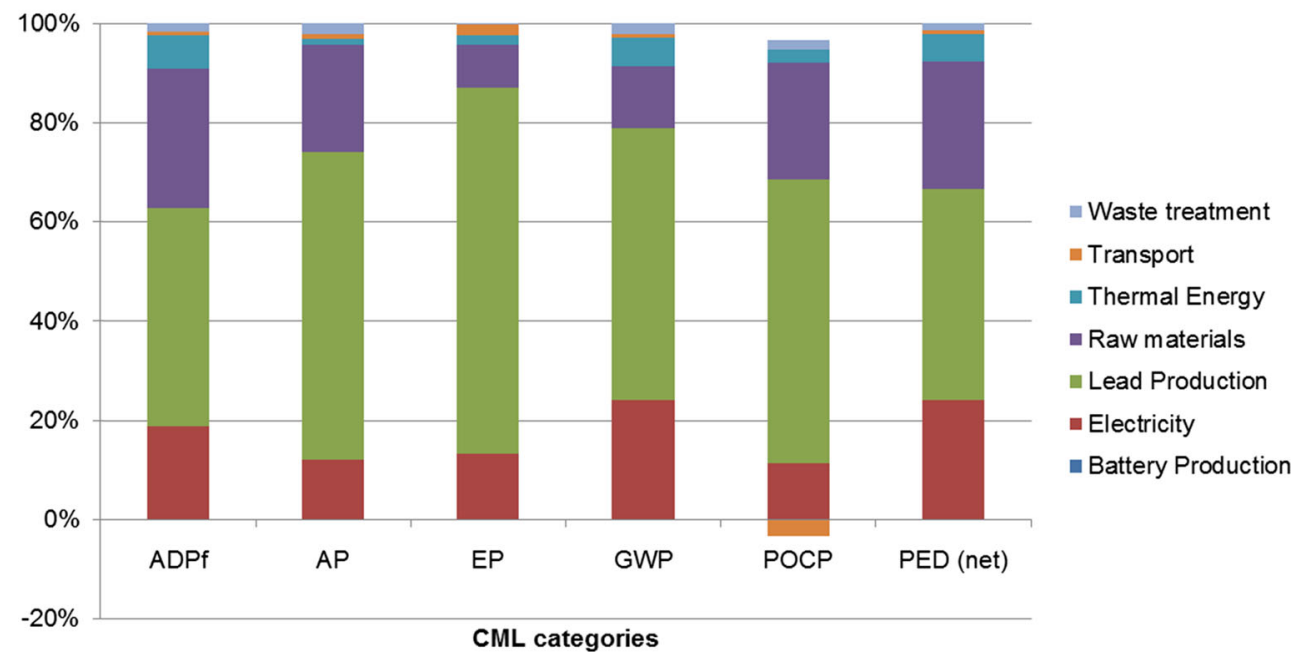

of lead-based batteries. The study concludes that the material production of lead contributes most dominantly to the studied environmental impacts from battery production.

The high recycling rates of lead-based batteries reduce the environmental impacts of batteries considerably. In the EU, more than $99 \%$ of automotive lead-based batteries are collected and recycled in a closed loop system (IHS 2014) - a rate of recycling higher than any other mass consumer products (BCI 2015). It should be mentioned here that the high recycling rates and high recycled content of lead batteries are much higher than other battery technologies, than other uses of lead, and most other applications using metals. These high recycling rates, coupled with the fact that lead batteries comprise over $80 \%$ recycled material (IHS 2014), dramatically reduce the need for the production of additional primary lead. As already stated, the conclusion of the LCA on lead production was that mining and smelting have the greatest environmental impacts for lead production. Hence, given that lead batteries comprise over $80 \%$ recycled lead, it can be expected that this will reduce the environmental impact associated with lead batteries (e.g. compared to lead batteries produced from a high proportion of primary material).
Fig. 8 Net impacts and savings associated with batteries required over vehicle-lifetime,

demonstrating the significant $\mathrm{CO}_{2}$ savings observed when using improved and advanced lead batteries

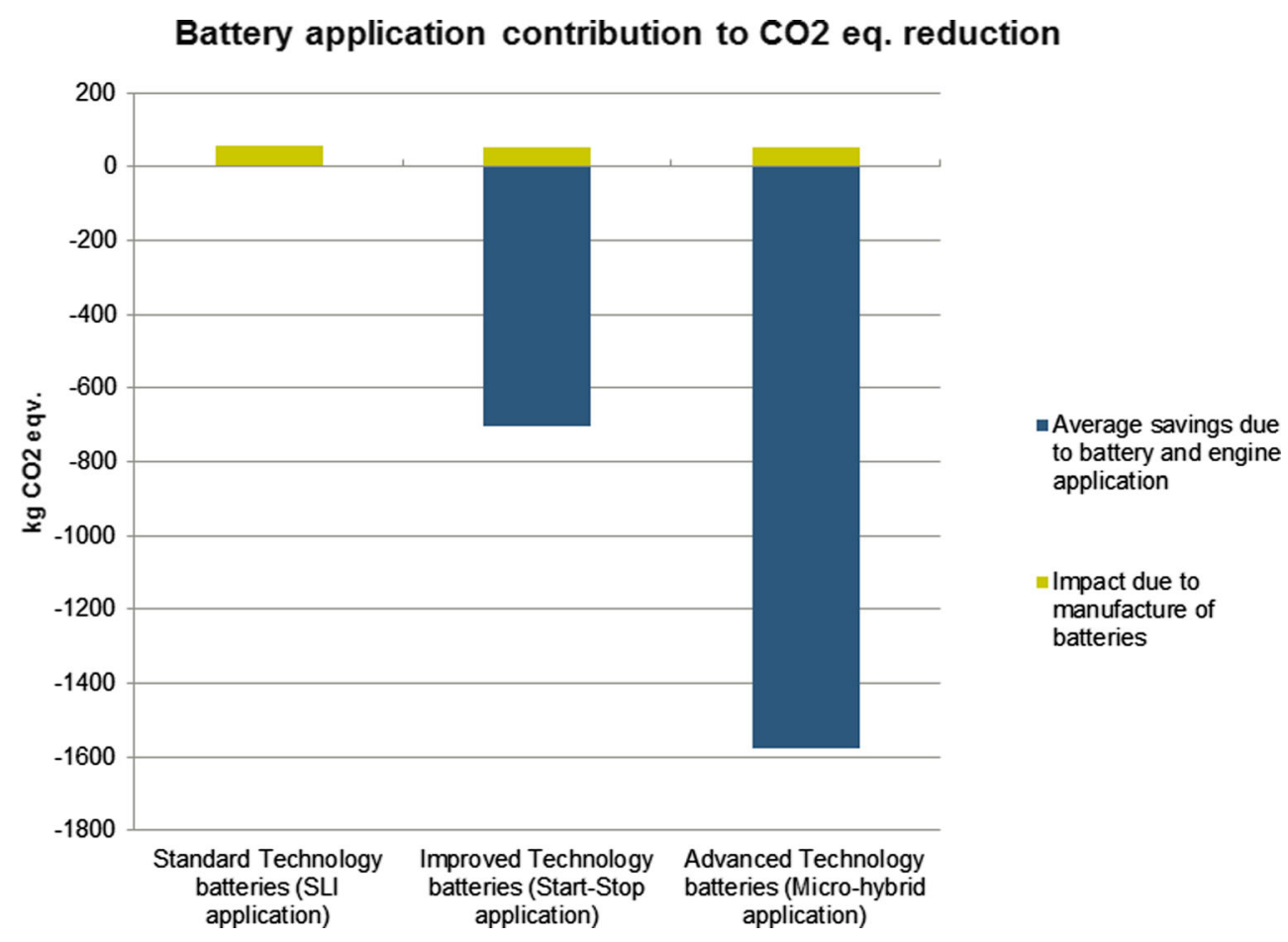


That the technological capabilities of advanced batteries in use offset the environmental impact of their production. The use of improved and advanced technology batteries offset the environmental impact caused through production by the considerable savings that they enable in global warming potential when installed in passenger vehicles. These batteries are integral parts of start-stop and micro-hybrid engine systems which have lower fuel consumption than regular engines. Over the lifetime of the vehicle, using these systems and batteries results in significant emission savings of carbon dioxide equivalent (as shown in Fig. 8).

\section{Architectural lead sheet LCA}

Lead sheet is widely used in the building and construction industries and is an attractive, effective, and traditional roofing material which provides long-term weatherproofing, either as sheeting or as flashing ${ }^{1}$ or weathering for chimney flashings, gutter and valley linings, roof apex caps, and other weatherings. It provides a completely watertight seal preventing rainwater leaks and so avoids damp and rot in homes and all other types of buildings. Some $85 \%$ of the total lead sheet demand is for this type of application (RPA 2014).

Globally, more than 100,000 t (International Lead Zinc Study Group 2015a, b) of lead sheet is used each year, principally in Belgium, France, Germany, Holland, Ireland, Spain, and the UK (International Lead Zinc Study Group 2008, Ullmann's Encyclopaedia of Industrial Chemistry 2015). Across the EU, there is an international standard which ensures the quality and consistency of the material (EN 12588 2006).

A study to analyse the environmental profile of lead sheets, through a cradle-to-gate life cycle assessment was conducted by PE INTERNATIONAL on behalf of the European Lead Sheet Industry Association (ELSIA) in 2014 (available via ELCD or ELSIA web page www.ELSIA.org). In common with the other lifecycle studies referred to in this paper, the study was conducted using methodologies defined by ISO Standards 14040 and 14044. It further acts as a follow up to a previous LCA on lead sheets conducted in 2006 (TNO). This study aimed to examine the environmental impacts associated with uncoated lead sheets produced in the European region (EU-27) - including the production in addition to recycling/end-of-life phases of the life cycle. A further analysis of impacts associated with the usage of the lead sheets in roofing was undertaken.

For the purposes of this study, results were calculated for $1 \mathrm{~kg}$ of uncoated lead sheet. Lead sheets in Europe vary from 1 to $4 \mathrm{~mm}$ in thickness. All lead sheets is manufactured from

\footnotetext{
${ }^{1}$ A flashing is a strip of metal used to stop water penetrating the junction of a roof with another surface.
}

recycled material. Figure 9 demonstrates the manufacturing stages covered by the study.

A typical market average thickness of $1.7 \mathrm{~mm}$ was considered in order to convert and present results in $1 \mathrm{~m}^{2}$ of lead sheet. This corresponds to an area density of $19.3 \mathrm{~kg} / \mathrm{m}^{2}$. The study took into account the high end-of-life recycling of lead sheet $(>95 \%)$ and the fact that all lead sheet is manufactured from recycled material. It should be mentioned here that the high recycling rates and high recycled content of lead sheet are much higher than most other metal sheet used in construction applications and other uses of lead (other than lead batteries) and most other applications using metals. The study had very good representation for the EU-27 production of lead sheet, with significantly over $80 \%$ coverage. In this study, there were no co-products produced in the foreground system. There was one valuable waste stream for recycling on the output-side of the refining step (lead dross), which is recirculated or 'looped' back into the refining stage The system boundaries of the study are shown in Fig. 10.

The CML characterisation method (Guinée 2001) was used in this study due to its mid-point approach and high level of scientific rigour. Between the time that this LCA was conducted and the lead battery LCA there, had been many developments and discussions in the realm of LCIA methods, e.g. in the context of the product environmental footprint (PEF) driven by the European Commission. The PEF is a new project which is focused on developing LCA-based methodology for assessing the environmental impact of products. The European Commission has selected a number of products for pilot projects to develop rules and criteria for calculating PEFs, which includes a project focusing on metallic sheet (including lead sheet). The PEF work includes consideration of additional impact categories, which is reflected in the list below. More information on the PEF can be found on the web site of the European Commission. The following

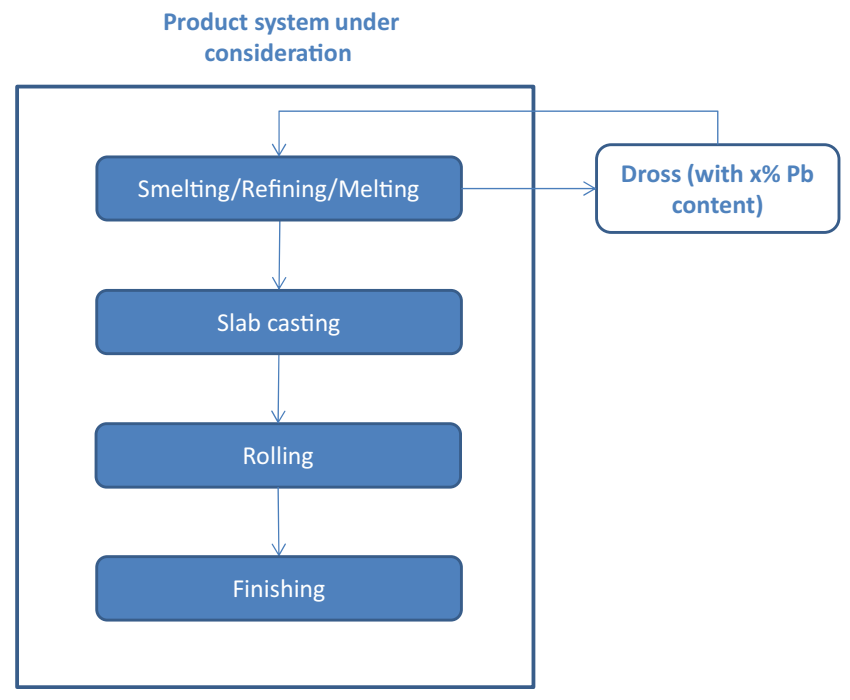

Fig. 9 Manufacturing stages covered in lead sheet LCA 
Fig. 10 System boundaries of lead sheet LCA

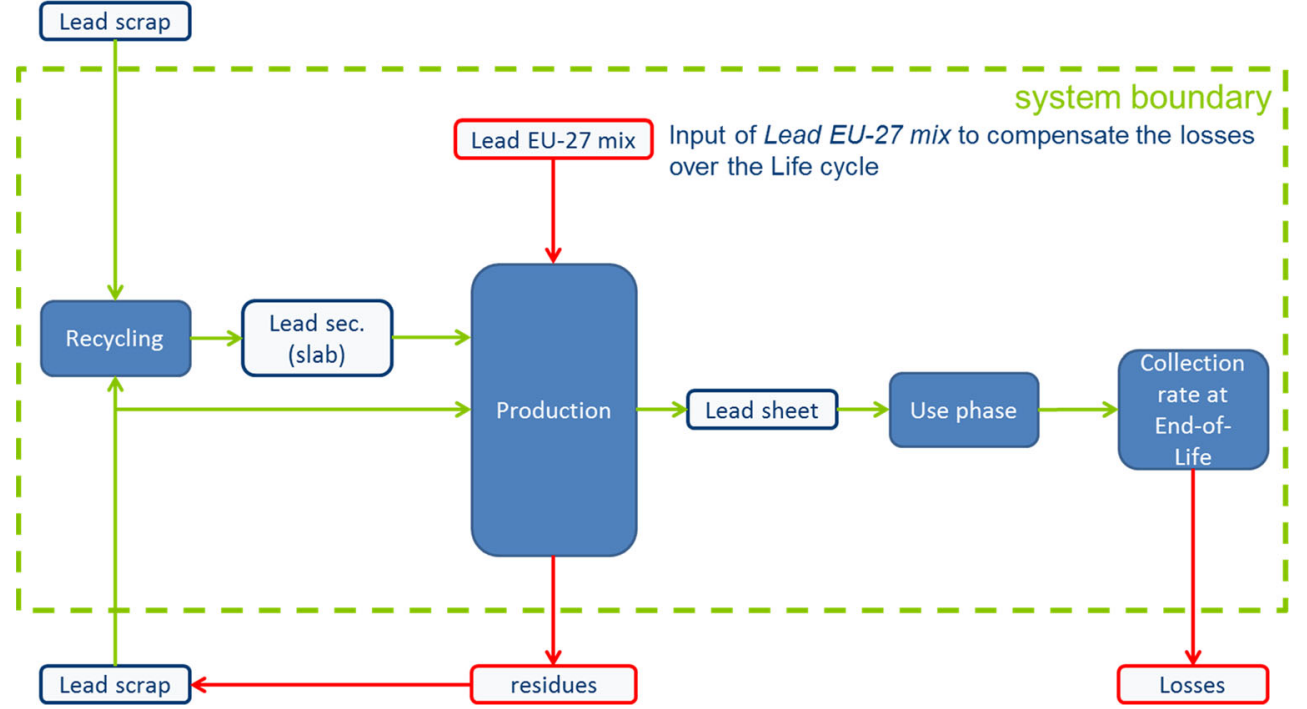

environmental impact categories and indicators were therefore considered in the scope of this study:

- Primary energy demand (renewable) (PEDreg) (MJ)

- Primary energy demand (fossil/non-renewable) (PEDnreg) (MJ)

- Global warming potential (GWP) (kg. $\mathrm{CO}_{2}$-equiv.)

- Acidification potential (AP) (kg. $\mathrm{SO}_{2}$-equiv.)

- Eutrophication potential (EP) (kg. phosphate-equiv.)

- Photochemical ozone creation (POCP) (kg. ethene-equiv.)

- Abiotic depletion potential (fossil, ADPf) (MJ)

\subsection{Results—sheet LCA}

In the CML impact categories, most of the impact ( $>85 \%)$ was discovered to stem from the production of lead metal, rather than the production of the sheet that results from the lead. An exception to this was ozone depletion potential, which also sees a significant share stemming from sheet production. This can be seen in Fig. 11, which shows the relative contribution to total impact for $1 \mathrm{~kg}$ of lead sheet.

Next to lead production, the major contributors to the impact categories were:

- Fuels - The fuels used in the production value chain were relevant to the global warming potential, abiotic depletion potential (fossil), and primary energy demand categories

- Transport-The transport (covering both scrap collection to lead sheet producer and from secondary lead ingot producers to lead sheet producer) modules were relevant contributors to the acidification potential, eutrophication potential, and photochemical ozone depletion potential impact categories
- Electricity-The electricity consumption and production was found to be a major contributor to ozone depletion potential and primary energy demand (renewable) categories

Analysis of the results shows a very small environmental impact associated with lead sheet production, compared for example with the secondary production of a lead ingot.

In addition, a sensitivity analysis was conducted for a lower collection rate. This scenario assumed a collection and recycling rate of $95 \%$ rather than $99 \%$, as a worst case assumption to test the influence of the parameter on the overall results. The effect was found to be negligible, leading to just a $0.3 \%$ deviation in the global warming potential.

As already stated, the conclusion of the LCA on lead production was that mining and smelting have the greatest environmental impacts for lead production. Given that all lead sheet is manufactured from recycled material and that over $95 \%$ is recycled at the end of life (EoL), it can be expected that the high recycling rates associated with lead sheet will reduces its environmental impact (e.g. compared to lead sheet produced from primary material).

\subsection{Socio-economic assessment using LCA data}

Following on from the Lead Sheet LCA study, a socioeconomic assessment was conducted using the LCA data (RPA 2014 internal report). Life cycle data was compiled from a number of sources in order to provide a comparative assessment of the relative impact of alternative roofing systems on the environment. This included comparisons with alternative building materials in a range of applications such as cavity wall (comparison with reinforced ethylene propylene diene monomer (EPDM) and PVC), flashing (comparison with reinforced polyisobutylene polymer (PiB)), and valley gutter 
Fig. 11 Relative contribution to total impact for 1-kg lead sheet (by module)

\section{Environmental impact - Modules}

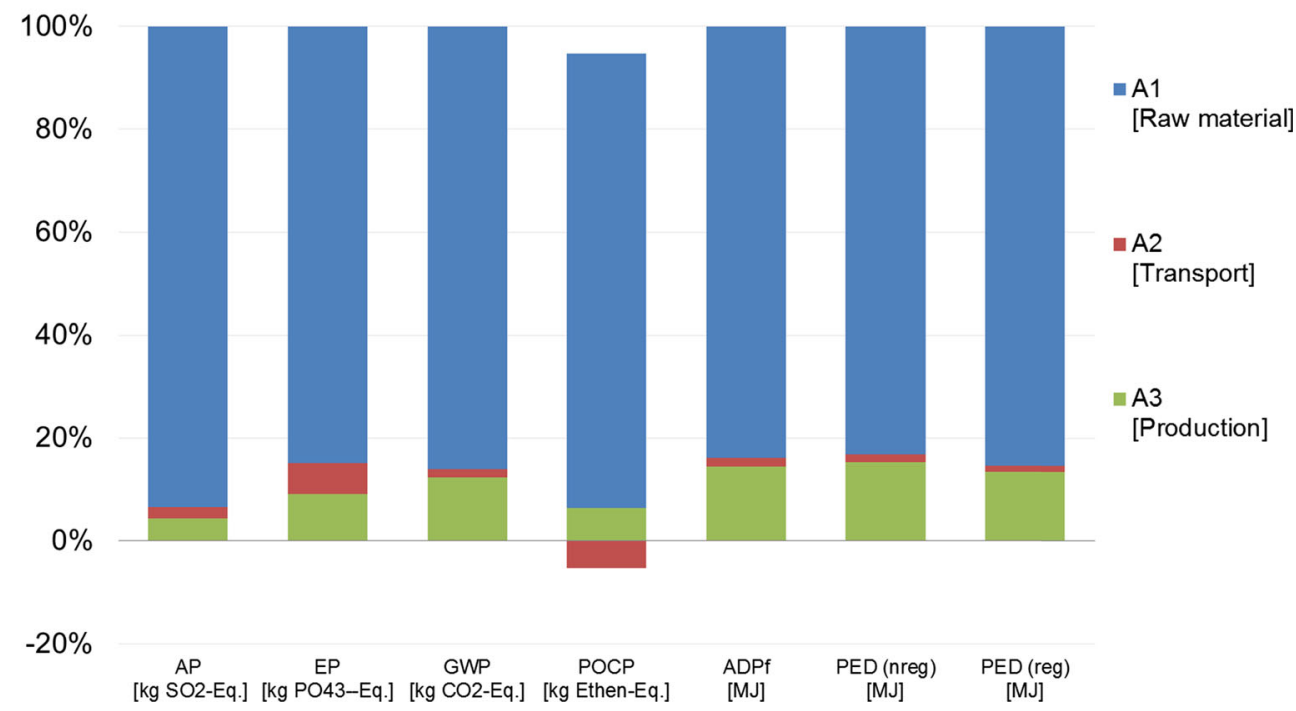

(comparison with glass fibre reinforced plastics (GRP)). A worst case lifespan of lead sheet was taken of 60 years, compared to 20 years for man-made alternatives. It should be stressed however that the comparative data presented here should be interpreted with caution as standardised methodology may not have been applied across all the studies. For example, due to methodological differences, the data presented in this section may take into account different stages of the lifecycle of a roofing material. The methodologies can be separated into two broad scopes: those that take into account all impacts up to the production stage and those that take into account the end-of-life and next product system stages (as well as the production stage). The data gathered from the LCAs are used, where possible, to give an indication of the energy demand requirements and $\mathrm{CO}_{2}$ equivalents produced under each of the scenarios for lead and its alternatives. Table 5 presents a summary table of the LCA data collected for the different stages for lead and man-made alternatives. The data have been recalculated and adjusted for a period of 85 years and thus take into account the expected service life of each material. Full life cycle values (production, end-of-life and next product system stages) are presented in parentheses. All other values are based on the production stage only.

From the table, it can be seen that lead sheet performs better than the selected alternatives on most measures. This is in part due to lead sheet's long service life, meaning that it needs replacing fewer times than the comparable alternatives. In particular, it can be seen that lead is the least energy intensive, due to its low melting point compared to the other materials and scores the lowest in terms of global warming potential.

Questions have been raised about the use of lead sheet as a roofing material due to concerns about human health impacts resulting from corrosion and run-off of lead. Like all materials, over time, exposed lead on rooftops and flashings will be subject to corrosion by the elements. A number of experimental studies have attempted to measure the amount of lead present in run-off from lead roofing over a period of years (Wilson 2003; EU Voluntary Risk Assessment Report 2008; Bos and Sonke 2003) and run-off rates of $0.88 \mathrm{~g} / \mathrm{m}^{2}$ for lead sheet flashings and $5 \mathrm{~g} / \mathrm{m}^{2}$ for roofing are typically assigned. Using these values, modelled exposure to children or adults arising from lead sheet used as roofing has been shown to be extremely low and well below any realistic level of detectable risk to an individual, representing less than $0.17 \%$ of the lead already ingested in the diet from other sources.

\subsection{Conclusion—sheet LCA}

- The study concluded that the high recycling rates associated with lead sheet reduces its environmental impact.

- The durability of lead sheet also added to its life cycle credentials - Over the longer term lead sheet becomes an even more attractive as a material for roofing applications, due to its extended service life (frequently longer than 60 years).

- Low generation of greenhouse gases - Lead sheet's low melting point allows recycling with minimal impact on global warming.

- Exposure to lead from corrosion and run-off from roofing is extremely low and does not represent a significant health risk.

- This data has also been used to demonstrate that lead sheet compares very well with alternative building materialsThe data highlights that lead sheet has a favourable environmental performance compared with alternative building materials in a range of applications such as: cavity wall (comparison with reinforced EPDM, platicised PVC, and 
Table 5 Environmental impacts for lead sheet and alternatives in roofing applications over 85 years

\begin{tabular}{llllll}
\hline Material & $\mathrm{ED} \mathrm{MJ} / \mathrm{m}^{2}$ & $\mathrm{GWP} \mathrm{kg} . \mathrm{CO}_{2} \mathrm{eq} / \mathrm{m}^{2}$ & $\mathrm{ODP} \mathrm{kg} . \mathrm{CFC}-11 \mathrm{eq} / \mathrm{m}^{2}$ & $\mathrm{AP} \mathrm{kg.} \mathrm{SO}_{2} \mathrm{eq} / \mathrm{m}^{2}$ & $\mathrm{ADP} \mathrm{kg} . \mathrm{Sb} \mathrm{eq} / \mathrm{m}^{2}$ \\
\hline $\begin{array}{l}\text { EPDM (ethylene propylene } \\
\quad \text { diene monomer) }\end{array}$ & $521.00(353.70)$ & $56.00(60.90)$ & $0.0000080(0.0000056)$ & $0.64(0.19)$ & $0.50(0.34)$ \\
$\begin{array}{l}\text { GRP (glass fibre reinforced } \\
\text { plastics) }\end{array}$ & - & $107.00(123.60)$ & $0.0000156(0.0000144)$ & $0.39(0.37)$ & $0.8015(0.726)$ \\
$\begin{array}{l}\text { Lead } \\
\text { Modified bitumen }\end{array}$ & $267.00(267.00)$ & $12.00(12.00)$ & $0.0000004(0.0000005)$ & $0.07(0.07)$ & $0.0287(0.0311)$ \\
$\begin{array}{l}\text { PVC } \\
\text { PiB (polyisobutylene polymer) }\end{array}$ & - & $241.50(170.00)$ & $0.0000241(0.0000151)$ & $1.25(0.74)$ & $2.04(1.164)$ \\
$\begin{array}{l}\text { TPO (thermoplastic } \\
\text { polyolefin polymer) }\end{array}$ & - & $218.00(125.00)$ & 0.0000016 & $4.15(0.43)$ & $0.95(0.716)$ \\
\hline
\end{tabular}

$E D$ energy demand, GWP global warming potential, $O D P$ ozone depletion potential, AP acidification potential, $A D P$ abiotic resource depletion potential Production only values are outside parentheses; production, end-of-life, and next product system values are inside parentheses. ED and GWP values have been rounded to nearest whole value; values for AP and ADP are rounded to two decimal places. References: Eurochlor (2013); Institut Bauen und Umwelt e.V. (Institute Construction and Environment) (2010); IPCC Climate Change (2007); Kalzip ® (2011); Fabre (2011); Owens (1997); Peters et al. (2011); TEGNOS Research Inc (2010); TNO (2006); UNEP (2000); US Environmental Protection Agency (2006); Protection Agency (2006)

${ }^{a}$ Recycling credits are included for lead

SEBS), flashing (comparison with reinforced PiB), and valley gutter (comparison with GRP).

\section{Overall conclusions}

Responding to requests from end users and regulators, and as part of the lead industry's own sustainable development goals, the International Lead Association (ILA) has conducted a range of detailed Life Cycle Assessments (LCA).

ILA has undertaken LCAs which investigate the environmental impact associated with the European production of lead metal and the most significant manufactured lead products (lead-based batteries used in vehicles and architectural lead sheet for construction) to ensure up to date and robust data is publically and widely available.

The main findings of the reports as follows:

Lead metal production LCI

- Mining and smelting have the greatest environmental impacts for lead production.

- The main contributors in mining and concentration are the fuel combustion and power production.

- Study represented $80 \%$ of production technology but only $32 \%$ of ILA members.

Lead-based batteries LCA

- Lead production (from ores or recycled scrap) is the dominant contributor to environmental impacts associated with the production of lead-based batteries.
- Vehicle production has a far greater lifecycle environmental impact than battery production $\left(9.9 \mathrm{t} \mathrm{CO}_{2}\right.$ per E300 Mercedes hybrid compared to 28 to $30 \mathrm{~kg} \mathrm{CO}_{2}$ per battery)

- The high recycling rates associated with lead-acid batteries dramatically reduce any environmental impacts.

- In terms of global warming potential, the environmental advantage of improved and advanced technology leadbased batteries during the use phase far outweighs the impacts of their production.

Architectural lead sheet LCA

- Most of the environmental lifecycle impacts of lead sheet result from lead production.

- High recycling rate of lead sheet reduce its environmental impacts.

- The durability and long service life of lead sheet adds to its life cycle credentials.

\section{Future work}

The lead industry aspires to provide stakeholders with a thoroughly transparent overview of the sustainability of its operations. ILA and its members believe that only with the use of lifecycle data of both lead and competing materials, society can make informed decisions regarding the environmental impacts and benefits associated with the materials and products manufactured from them.

ILA members are committed to improving the environmental performance of lead production and manufacture of 
its products. To assist in this effort, ILA will continue to gather robust and quality LCA data. This is expected to include updating the lead production LCI to ensure a more comprehensive representation of European manufacturing but also to perform lifecycle assessment of both lead production and lead products on a more global basis.

Open Access This article is distributed under the terms of the Creative Commons Attribution 4.0 International License (http:// creativecommons.org/licenses/by/4.0/), which permits unrestricted use, distribution, and reproduction in any medium, provided you give appropriate credit to the original author(s) and the source, provide a link to the Creative Commons license, and indicate if changes were made.

\section{References}

ACEA (2015) (European Automobile Manufacturers Association) http:// www.acea.be/publications/article/life-cycle-assessment-lca-of-leadbased-batteries-for-vehicles

BCI (2015) The facts about lead energy solution. Available at http://c. ymcdn.com/sites/batterycouncil.org/resource/resmgr/Brochures/ BCI_Sustainability_recycling.pdf

Bos WM, Sonke J (2003) Experimental study of new lead alloys for atmospheric application, TNO Report CA03.8010

EN 12588 (2006) Lead and lead alloys. Rolled lead sheet for building purposes

EU Risk Assessment Report (2008). Voluntary risk assessment of lead metal, lead oxide, lead tetraoxide and lead stabiliser compounds. Available at http://echa.europa.eu/web/guest/voluntary-riskassessment-reports-lead-and-lead-compounds

Eurochlor (2013) Life cycle assessment, issue 04, edition 2013, available at: http://www.eurochlor.org/media/40457/04_life_cycle_ assessment.pdf

European life cycle database available at http://eplca.jrc.ec.europa.eu/ ELCD3/

Fabre G (2011) LCB Method (Low carbon buildings method) available at: http://www.lcbmethod.com/appendix.pdf

Guinée et al. (2001) An operational guide to the ISO-standards, Centre for Milieukunde (CML), Leiden, the Netherlands

IHS (2014) The availability of automotive lead-based batteries for recycling in the EU. Available at http://www.eurobat.org/sites/ default/files/ihs_eurobat_report_lead_lores_final.pdf

Institut Bauen und Umwelt e. $\overline{\text { V. }}$. (Institute Construction and Environment) (2010) Roofing and waterproofing membrane system EVALASTIC ®, available at: http://alwitra.de/wpcontent/uploads/2013/05/ alwitra_EVALASTIC_EPD.pdf

International Lead Zinc Study Group (ILZRO) http://www.ilzsg.org

International Lead Zinc Study Group (2008) Principal uses of lead and zinc. Available via http://www.ilzsg.org

International Lead Zinc Study Group (2015) Lead-acid industrial batteries. Available via http://www.ilzsg.org

International Lead Zinc Study Group (2015) monthly bulletin. Available via http://www.ilzsg.org

IPCC climate change (2007): the physical science basis, IPCC fourth assessment report (AR4), available at: http://www.ipcc.ch/
ISO 14040 (2006) Environmental management—-life cycle assessment— principles and framework

ISO 14044 (2006) Environmental management-life cycle assessmentrequirements and guidelines

Joint industry analysis (2014) A review of battery technologies for automotive applications. Available via http://www.acea.be/publications/ article/a-review-of-battery-technologies-for-automotiveapplications

Kalzip ® (2011): Environmental product declaration, available at: http:// www.kalzip.com/PDF/eur/Kalzip_EPDsECO.pdf

Kerdlap P (2014) The life cycle environmental impacts and life cycle costs of electric motorcycles/Bangkok University of Technology. Available at http://transportandclimatechange.org/wp-content/ uploads/2015/03/Electric-two-wheelers-in-Thailand-02-03-2015final.pdf accessed February 2015

Matheys J et al. (2006) Comparison of the environmental impact of 5 electric vehicle battery technologies using LCA

Owens JW (1997) Life-cycle assessment: constraints on moving from inventory to impact assessment, available at: http://www.utexas. edu/research/ceer/greenproduct/dfe/PDF/constraints_on_moving. pdf

Peters GP et al (2011) Alternative "global warming" metrics in life cycle assessment: a case study with existing transportation data. Environ Sci Technol 45(20):8633-41, available at: http://www.ncbi.nlm.nih. gov/pubmed/21936535

Protection Agency (2006) Life cycle assessment: principles and practice, available at: http://www.epa.gov/nrmrl/std/lca/pdfs/chapter4lca101. pdf

Risk \& Policy Analyst (RPA) http://rpaltd.co.uk/

Santero N, Henry J (2014) Harmonization of LCA methodologies for the metals and mining industry. Available at https://www.icmm.com/ document/6657

Sullivan JL, Gaines L (2010) Argonne National Laboratory A review of battery life-cycle analysis: state of knowledge and critical needs

TEGNOS Research Inc. (2010) Life cycle inventory and Assessment of Selected Low Slope Roofing Systems in North America, prepared for the EPDM Roofing Association, available at: http://www. epdmroofs.org/epdm-todays-choice/2010_05_30_ LifeCycleInventoryAssessmentOfSelectedLowSlopeRoofing SystemsInNorthAmerica.pdf

TNO (2006) Environmental performance of lead sheet and alternative weather-proofing products, study for ELSIA, available at: www. frerikswerken.nl/images/nieuws/TNO_lood.pdf

Ullmann's Encyclopaedia of Industrial Chemistry (2015) UmweltZertifikat für den E300 BlueTEC Hybrid; Availble at https://www. daimler.com/Projects/c2c/channel/documents/2218808_UZ_E_ 300_BTH_de.pdf

UNEP (2000) Assessing the impacts of short-lived compounds on stratospheric ozone, Report to the United Nations Environment Programme from the Cochairs of the Montreal Protocol, Scientific Assessment Panel

Universität Stuttgart und PE International AG (2006) GaBi: Software und Datenbank zur Ganzheitlichen Bilanzierung. IKP. LeinfeldenEchterdingen, Germany

US Environmental Protection Agency (2006) Chapter 4, Life cycle impact assessment, in US environmental

Wilson DN (2003) Atmospheric corrosion of lead. European Lead Industry Association. In: UNECE Workshop on releases of heavy metals from materials due to corrosion. 12-14 May 2003, Munich 